\title{
De harde noodzaak van
} soft-controls

\section{Een onderzoek naar zorgvuldig financieel en materieel beheer bij}

\section{Defensie}

\section{J. Heeren-Bogers, M. Kaptein en J. Soeters}

SAMENVATTING Het Ministerie van Defensie kampt al geruime tijd met negatieve beoordelingen van de Algemene Rekenkamer over het financieel en materieel beheer. Defensie heeft zich daarbij gericht op het verder aanscherpen van regels, procedures en bevoegdheden. De vraag is echter of het verbeteren van dergelijke hardcontrols voldoende is. Dit artikel onderzoekt dan ook de toegevoegde waarde van soft-controls. Op basis van een vragenlijstonderzoek onder medewerkers van Defensie wordt aangetoond dat soft-controls een belangrijke verklaring bieden voor de mate van onzorgvuldig beheer. Daarmee bieden soft-controls aanknopingspunten voor verbetering van het beheer.

\section{RELEVANTIE VOOR DE PRAKTIJK In dit onderzoek zijn harde en zachte beheer-} singsmaatregelen in samenhang bekeken. Het onderzoek toont aan dat soft-controls een belangrijke aanvulling zijn op hard-controls. Voor degenen die verantwoordelijkheid dragen voor het beheer binnen organisaties dan wel de controle en toezicht daarop, laat dit artikel zien dat soft-controls daarin dienen te worden betrokken.

\section{Inleiding}

Net als voor veel andere organisaties, is financieel beheer - zijnde het begroten, verrichten, vastleggen van en verantwoording afleggen over financiële transacties - en materieel beheer - zijnde de zorg voor niet-geldelijke bronnen vanaf het moment van ontvangst tot aan het moment van afstoting - (Ministerie van Financiën, 2003), van belang voor het Ministerie van Defensie. Dit is van belang omdat zorgvuldig beheer wettelijk is voorgeschreven in de Comptabiliteitswet (artikel 22 en $25 \mathrm{CW}$ ) evenals dat zorgvuldig beheer geboden is voor de legitimiteit en goede reputatie van het ministerie. Desalniettemin constateert de Algemene Rekenkamer (ARK) al geruime tijd onvolkomenheden in het financieel en materieel beheer bij Defensie. In het rapport bij het Jaarverslag 2008 van het Ministerie van
Defensie waarschuwde de ARK ervoor dat Defensie mogelijk niet haar operationele doelstellingen zou bereiken en besloot de ARK een bezwaaronderzoek in gang te zetten. ${ }^{1}$ Defensie riep vervolgens het project 'Beter Verbeteren' in het leven. Het projectteam nam vooral de hard-controls zoals procedures, functiescheiding en interne controle ter hand. Als reactie daarop heeft de ARK in mei 2009 besloten het bezwaaronderzoek niet voort te zetten. Van tevreden achteroverleunen kon echter geen sprake zijn, aldus de toenmalige Minister van Defensie: "Het is van het grootste belang dat de aandacht voor goed beheer wordt vastgehouden. Nu de aandacht laten verslappen, betekent dat we mogelijk weer op afstand komen" (Ministerie van Defensie, 2009).

De ARK constateerde echter in haar rapport over het Jaarverslag 2010 van het Ministerie van Defensie dat de uitvoering van de meerjarige verbeterplannen achterliep. "Gezien het grote aantal onvolkomenheden (22, één minder dan vorig jaar) en de hardnekkigheid van de meeste daarvan, achten we het van groot belang dat het beheer verder op orde wordt gebracht" aldus de ARK (2011, p. 5 ). De vraag is echter of met het verbeteren van hardcontrols de gewenste verbetering überhaupt kan worden gerealiseerd. Onderzoek door Vink en Kaptein (2008) binnen de Rijksoverheid naar de oorzaken van rechtmatigheidsfouten laat namelijk zien dat geen van de fouten werd veroorzaakt door louter falende hard-controls. Bij $80 \%$ van de fouten bleek namelijk dat de fouten mede werden veroorzaakt door tekortschietende soft-controls. In de overige gevallen waren zelfs louter falende soft-controls de oorzaak van de rechtmatigheidsfouten. De vraag is dan ook in hoeverre soft-controls binnen het Ministerie van Defensie een oorzaak zijn voor de onzorgvuldigheden in het beheer en in hoeverre dus moet worden ingezet op het verbeteren van de soft-controls om de onvolkomenheden te verminderen. 
Ten behoeve van dit artikel hebben wij daarom onderzoek verricht onder defensiemedewerkers naar de aanwezigheid van hard- en soft-controls ten aanzien van het beheer en de mate waarin dit van invloed is op de zorgvuldige omgang met de financiële en materiële middelen. Dit onderzoek is daarmee een weergave van de nulmeting bij Defensie op het gebied van de relatie tussen beheersingsmaatregelen en zorgvuldigheid van beheer en is daarmee een vorm van cross-sectioneel onderzoek. Ondanks het nadeel van cross-sectioneel onderzoek dat daarmee niet is vast te stellen hoe relaties zich in de tijd ontwikkelen, biedt het wel de mogelijkheid inzicht te verkrijgen in hoe relaties zich op een gegeven moment manifesteren. Voordelen zijn verder dat het eenvoudig, goedkoop en minder belastend voor het werkveld is.

Dit onderzoek gaat verder dan dat van Vink en Kaptein (2008). Zij hebben voor dertig geconstateerde rechtmatigheidsfouten in de jaarverslagen 2006 van de Rijksoverheid de twintig betrokken auditors geïnterviewd om te achterhalen of deze fouten worden veroorzaakt door hard-controls, soft-controls of een combinatie van beide. Vink en Kaptein (2008, p. 263) onderkennen het bevragen van auditors als een belangrijke beperking van hun onderzoek. Ten eerste zijn auditors opgeleid en getraind in het detecteren van fouten in hard-controls, hetgeen kan leiden tot onevenredig veel aandacht voor hard-controls als oorzaak voor rechtmatigheidsfouten. Ten tweede kunnen auditors de oorzaak van rechtmatigheidsfouten meestal niet direct waarnemen, maar veelal pas later en aan de hand van achterliggende documentatie en observaties de mogelijke oorzaken inschatten. Wij zijn aan deze beperking tegemoet gekomen door aan de gebruikers van de financiële en materiële middelen zelf te vragen naar hun perceptie van hard- en soft-controls zodat we daardoor een beter beeld krijgen van de oorzaken van hun zorgvuldige dan wel onzorgvuldige omgang met de middelen. Daarnaast hebben wij door grootschalig enquêteonderzoek te verrichten van 600 respondenten informatie verzameld waardoor het mogelijk is verbanden statistisch te toetsen.

Door dit onderzoek hopen we te illustreren op welke wijze hard- en soft-controls van invloed zijn op het beheer binnen organisaties en de wijze waarop dit de omgang van managers en medewerkers met de financiële en materiële middelen beïnvloedt. Dergelijk wetenschappelijk onderzoek is nog niet binnen andere organisaties verricht. Het biedt daarom een impuls voor vervolgonderzoek.

De opbouw van dit artikel is als volgt. In de volgende paragraaf komen wij tot de formulering van vijf hypothesen. Vervolgens bespreken wij de opzet van ons empirisch onderzoek en de resultaten daarvan. Het artikel sluit af met de conclusies en implicaties.

\section{Hypothesen}

Financieel en materieel beheer zijn voor veel organisaties relevant. Voor Defensie betekent financieel beheer het voldoen aan de vastgelegde procedures en externe en interne regelgeving bij het verrichten van, het registreren van en de verantwoording over de financiële gevolgen van transacties die Defensie uitvoert (Meerjarig Verbeterplan Financieel Beheer, 2009). Het financieel beheer is daarbij in de volgende financiële elementen onderverdeeld: uitgaven, verplichtingen, vorderingen en ontvangsten, voorschotten, rekeningen buiten begrotingsverband en liquide middelen. Materieel beheer bij Defensie is de zorg voor roerende zaken, financiële middelen uitgezonderd, vanaf het moment van ontvangst tot aan het moment van afstoting (Voorschrift Materieelbeheer Defensie, 2009). De volgende elementen worden daarbij onderscheiden: munitiebeheer, wapenbeheer, cryptobeheer en overig materieel beheer. Aan de soorten van materieel beheer valt af te lezen dat het niet alleen om het zorgvuldig omgaan met overheidsgeld gaat. Onzorgvuldig materieel beheer zou er immers toe kunnen leiden dat materieel in verkeerde handen valt met potentieel gevaar voor de samenleving.

Om zorgvuldig beheer te stimuleren en te waarborgen kunnen organisaties controls inzetten. Controls binnen organisaties zijn erop gericht om het gedrag van managers en medewerkers te beïnvloeden teneinde organisatiedoelen te bereiken (Anthony, 1965; Lawler \& Rhode, 1976; Merchant, 1982). Controls willen wij in lijn hiermee binnen organisatieverband definiëren als de maatregelen om het gedrag van managers en medewerkers te beïnvloeden. Het gaat hierbij om zowel het voorkómen van ongewenst gedrag, zoals fouten, ongelukken, incidenten en overtredingen, als het bevorderen van gewenst gedrag, zoals rechtmatigheid, effectiviteit en efficiency.

Controls zijn onder andere onder te verdelen in hardcontrols en soft-controls. Roth (1998) heeft het onderscheid tussen soft- en hard-controls geïntroduceerd. Soft-controls zijn volgens Roth ontastbaar, terwijl hard-controls tastbaar zijn. Volgens De Heus en Stremmelaar (2000) wordt het onderscheid tussen hard- en soft-controls gemaakt door de mate waarin het de persoon beïnvloedt ofwel op basis van de effecten van de controls. Soft-controls gaan dieper en beïnvloeden de overtuiging of zelfs de persoonlijkheid van de medewerkers, terwijl de hard-controls meer zijn gericht op het gedrag en de vaardigheden. Volgens Vink en Kaptein (2008) is het typerende van soft-controls gelegen in de aard van de beheersingsmaatregel. Onderscheidend is volgens hen dat soft-controls informele beheersingsmaatregelen zijn, terwijl hard-controls formele maatregelen zijn. In dit artikel volgen wij de definities van Vink en Kaptein (2008) omdat het typerende van hard- en soft-controls ons inziens niet is gelegen in de soort invloed die de beheersingsmaatregel heeft, maar 
in de aard van de maatregel. Het is immers aannemelijk dat beheersingsmaatregelen een verschillende uitwerking hebben op verschillende personen.

Om zorgvuldig beheer te stimuleren en te waarborgen kunnen organisaties hard-controls inzetten. Hard-controls zijn de expliciet vastgestelde en vastgelegde maatregelen binnen de organisatie, inclusief de uitvoering daarvan zoals beleid, systemen en handboeken (Vink $\&$ Kaptein, 2008). Ze hebben als doel gewenst gedrag af te dwingen door bijvoorbeeld procedures, functiescheidingen en administratieve systemen. Er is een positief effect te verwachten van hard-controls op de zorgvuldigheid van het beheer. Derhalve luidt onze eerste hypothese:

Hypothese 1: Hoe beter hard-controls zijn ingebed in Defensie, des te zorgvuldiger managers en medewerkers omgaan met de financiële en materiële middelen.

Naast hard-controls kunnen organisaties ook beschikken over soft-controls. De belangstelling voor soft-controls als verklaring voor onrechtmatig gedrag is toegenomen sinds de boekhoudschandalen van Enron en Worldcom in 2002. Traditioneel wordt de oorzaak van dergelijke fouten gezocht in het falen van hard-controls. Onderzoek van Mouthaan (2007) laat echter zien dat de oorzaak van de boekhoudschandalen niet alleen de slechte formele, maar juist ook de slechte informele beheersingsstructuur was. Sims en Brinkmann (2003) beschrijven eveneens dat de organisatiecultuur van Enron een atmosfeer van onethisch en illegaal gedrag creëerde. Er is derhalve een positief effect te verwachten van soft-controls op de zorgvuldigheid van het beheer. Dit leidt tot de volgende hypothese:

Hypothese 2: Hoe beter soft-controls zijn ingebed in Defensie, des te zorgvuldiger managers en medewerkers omgaan met de financiële en materiële middelen.

Naast soft-controls kan de typische cultuur van een organisatie van invloed zijn op de mate waarin managers en medewerkers zorgvuldig omgaan met de financiële en materiële middelen van hun organisatie. Soft-controls zijn de generieke condities. Zo spreekt Kaptein (2008) over helderheid van normen, voorbeeldgedrag en handhaving. Cultuur kan eveneens betreffen de specifieke in de organisatie heersende opvattingen over wat goed en slecht is (Schein, 1985). De specifieke cultuur kan een positieve dan wel negatieve invloed op beheer hebben. De invloed kan positief zijn als de managers en medewerkers van een organisatie een juiste en sterk gedeelde opvatting hebben over wat zorgvuldig en onzorgvuldig beheer is. Als deze sterk gedeelde opvatting ontbreekt of als de gedeelde opvatting niet is gericht op zorgvuldig beheer, heeft dat een negatieve invloed op het feitelijk zorgvuldig beheer.
Wij verwachten dat het bestaan van subculturen bij de defensieonderdelen de mate van kostenbewustzijn bij medewerkers van Defensie beïnvloedt (Soeters, 2000). Dit komt overeen met het onderscheid dat Hofstede (1991) maakt in proces- en resultaatgerichte culturen. Procesgerichte organisatiedelen worden gekenmerkt door een gerichtheid op middelen en resultaatgerichte organisatiedelen zijn gericht op het halen van de doelen. Werknemers van de operationele commando's zijn verantwoordelijk voor de drie hoofdtaken van defensie. Zij willen waarschijnlijk bij de beslissingen over de uitvoering van deze taken geen rekening houden met de kosten. Deze houding ten aanzien van kosten wordt veroorzaakt door het feit dat de primaire taken als belangrijker worden gezien. Er kan een parallel worden getrokken met de cultuur in de gezondheidssector. Deze cultuur kent een expliciete expressie van normen en waarden doordat het doel om mensenlevens te beschermen boven iedere andere doelstelling wordt geplaatst (Snider, 1999). De ondersteunende defensieonderdelen daarentegen zijn niet direct betrokken bij het uitvoeren van de drie hoofdtaken. Dit deel van de organisatie kan worden vergeleken met een normale kantooromgeving waar regels, strategische planning en het beheersen van de kosten gemeengoed zijn. Gebaseerd op deze redenering verwachten wij dat de specifieke militaire professionele cultuur een negatieve invloed heeft op kostenbewustzijn en daarmee op beheer. Onze derde hypothese luidt derhalve:

Hypothese 3: Hoe hoger de mate van militaire professionele cultuur, hoe lager het niveau van kostenbewustzijn is van managers en medewerkers en vervolgens hoe onzorgvuldiger het financieel en materieel beheer binnen Defensie is.

Het erkennen en toepassen van hard-controls vormt voor medewerkers een richting over hoe men zich dient te gedragen zodat de zorgvuldigheid van het beheer toeneemt. ${ }^{2}$ Dit leidt tot de volgende hypothese:

Hypothese 4: Het effect van militaire professionele cultuur op beheer wordt positief beïnvloed door de toepassing van hard-controls.

Soft-controls, worden geassocieerd met commitment zodat werknemers hun gedrag voornamelijk zelf reguleren in plaats van dat hun gedrag is gebaseerd op externe druk en sancties. De mate waarin er bij een organisatie sprake is van zelfregulerende, zelfvoorzienende en zichzelf corrigerende capaciteit (Kaptein, 2008, p. 924) kan leiden tot zorgvuldiger beheer ondanks de militaire professionele cultuur. Dit leidt tot de volgende hypothese: 
Figuur 1 Conceptueel model

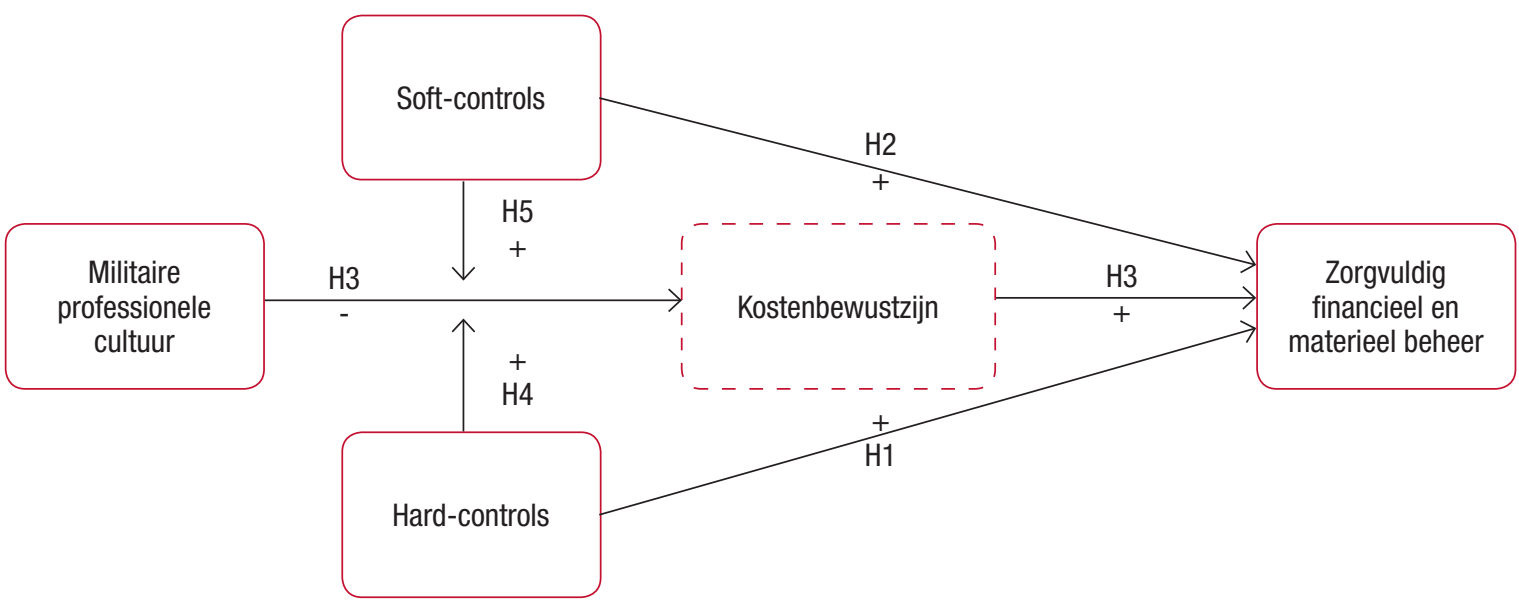

Hypothese 5: Het effect van militaire professionele cultuur op beheer wordt positief beïnvloed door de toepassing van soft-controls.

De vijf hypothesen voor dit onderzoek staan weergegeven in figuur 1 .

\section{Methode van onderzoek}

Om de hypothesen te toetsen hebben wij onderzoek verricht binnen alle zeven onderdelen van het Ministerie van Defensie, te weten het Commando Landstrijdkrachten, het Commando Zeestrijdkrachten, het Commando Luchtstrijdkrachten, de Koninklijke Marechaussee, de Bestuurstaf, de Defensie Materieel Organisatie en het Commando Dienstencentrum. Van ieder defensieonderdeel is aselect $20 \%$ van de daaruit bestaande eenheden genomen. Van de in totaal 111 geselecteerde eenheden hebben steeds minimaal tien medewerkers die een verantwoordelijkheid op het gebied van financieel en/of materieel beheer hebben, een vragenlijst gekregen. ${ }^{3}$ Van de 1.162 verstuurde vragenlijsten zijn er 600 volledig ingevuld retour ontvangen, hetgeen een responspercentage van $52 \%$ inhoudt.

Om de betrouwbaarheid te bepalen, oftewel na te gaan of de items op een consistente wijze het construct weergeven wat ze meten (Field, 2009, p. 673), is voor iedere construct, indien mogelijk de Cronbachs alpha $(\alpha)$ bepaald. Deze $\alpha$ geeft aan in hoeverre die items inderdaad hetzelfde concept meten, door te berekenen of de antwoorden van een grote groep respondenten op deze items consistent zijn. Hierbij hebben wij de gebruikelijke norm van een $\alpha$ van ten minste 0,70 gehanteerd (Cortina, 1993). Als de $\alpha$ lager was dan 0,70 dan hebben we gekeken welke items moesten worden weggelaten om tot een voldoende betrouwbaarheid te komen. In bijlage 1 zijn de overgebleven items opgenomen van zowel de afhankelijke, de onafhankelijke als de controlevariabelen.

\section{Afhankelijke variabelen financieel en materieel beheer}

Voor zowel financieel als materieel beheer zijn drie constructen gehanteerd. Het eerste construct is zorgvuldigheid. Zorgvuldigheid is de mate waarin de respondenten het beheer binnen hun eenheid als zorgvuldig zien. Dit is gemeten op een zespuntsschaal van 1 (zeer onzorgvuldig) tot 6 (zeer zorgvuldig). Zorgvuldig financieel beheer is gemeten aan de hand van zes items met een $\alpha$ van 0,91 . Zorgvuldig materieel beheer is gemeten aan de hand van vier items met een $\alpha$ van 0,77.

Het tweede construct meet het tegenovergestelde, namelijk de frequentie van onzorgvuldigheden in het financieel en materieel beheer. De frequentie van onzorgvuldigheden is gemeten met één item. De zespuntsschaal loopt uiteen van nooit tot dagelijks.

Het derde construct, besparingsmogelijkheden, geeft een indicatie van de omvang van onzorgvuldig gedrag. Respondenten is gevraagd naar de mate waarin hun eenheid op de uitgaven zou kunnen besparen als er sprake zou zijn van zorgvuldig financieel en materieel beheer. Zij konden dit aangeven op een schaal van 0 tot $100 \%$.

\section{Onafhankelijke variabele, hard-controls}

Het construct hard-controls is geoperationaliseerd door voor vijf hard-controls op een zevenpuntsschaal $(0=\mathrm{ik}$ weet het niet, $1=$ volledig mee oneens tot $6=$ volledig mee eens) de respondenten te vragen naar de opzet, bestaan en werking ervan. Dit betreft controletechnische functiescheiding, interne controle, procedurebeschrijvingen/richtlijnen/regelgeving, registratie en risicoanalyse (zie Jans, 2007). De $\alpha$ voor deze 15 items bedraagt 0,91 .

\section{Onafhankelijke variabele, soft-controls}

Voor het bepalen van de mate waarin soft-controls aanwezig zijn is gebruikgemaakt van de door Kaptein (2008) ontwikkelde schaal, waarbij de vragen op een zes- 
puntsschaal van 1 (volledig mee oneens) tot 6 (volledig mee eens) zijn toegesneden op financieel en materieel beheer. De $\alpha$ voor de 35 items van financieel beheer is 0,93 en voor de 33 items van materieel beheer is 0,92 .

\section{Onafhankelijke variabele, militaire professionele cultuur}

Omdat er geen schaal is voor militaire professionele cultuur is dit gemeten met behulp van een proxy. Daarvoor zijn drie items gehanteerd, te weten of de respondenten militair of burger zijn, indien zij militair zijn, de soort militair - waarbij er onderscheid is gemaakt in special forces (bijvoorbeeld mariniers), gevechtsfuncties (bijvoorbeeld infanterie), primair ondersteunende functies (bijvoorbeeld geneeskundige dienst) en secundair ondersteunende functies (bijvoorbeeld militaire administratie) - en de mate van uitzenddruk variërend van nooit, 1 tot 3 keer en meer dan 4 keer. Door een combinatie van de antwoorden op deze drie vragen te maken, zijn waarden toegekend van 1 tot 13 , waarbij een hogere waarde aangeeft dat er meer sprake is van een militaire professionele cultuur. ${ }^{4}$ Omdat dit construct een proxy is kan de alpha hiervan niet worden bepaald.

\section{Onafhankelijke variabele, kostenbewustzijn}

Kostenbewustzijn is gemeten aan de hand van een door Bovier, Martin en Perneger (2005) ontwikkelde schaal binnen de gezondheidszorg. Hiervoor hebben wij de vragen toegesneden op de defensiepraktijk. Vier van de acht items, gemeten op een zespuntsschaal van 1 (volledig mee oneens) tot 6 (volledig mee eens), vormen een $\alpha$ van 0,69 .

\section{Controlevariabelen}

De hypothesen worden gecontroleerd voor een aantal variabelen waarvan wordt verwacht dat ze invloed hebben op de veronderstelde relaties. De eerste controlevariabele is geslacht. Er is veel onderzoek gedaan naar de ethische percepties van mannen en vrouwen, met uiteenlopende resultaten. Toch is de algemene lijn dat mannen, meer dan vrouwen, onethisch gedrag vertonen en dat vrouwen, meer dan mannen, eerder bepaald gedrag als onethisch bestempelen (Beu, Buckley \& Harvey, 2003).

Naast geslacht kan leeftijd een rol spelen in de relaties. Uit onderzoek van Kim en Choi (2003) blijkt dat oudere respondenten een hogere mate van idealisme en een lagere mate van relativisme hebben. Daarnaast committeren oudere respondenten zich meer aan de professionele standaarden op het gebied van ethiek. De derde controlevariabele is opleidingsniveau. Ook hier zijn de resultaten van eerder onderzoek uiteenlopend, maar de meeste tonen aan dat hoe hoger het opleidingsniveau, hoe vaker bepaald gedrag als onethisch wordt gezien (Deshpande, 1997).

De laatste controlevariabele is 'span of control'. Detert et al. (2007) veronderstellen dat managers onethisch gedrag tegen kunnen gaan door de mogelijkheid voor dit gedrag te beperken door een hoge mate van 'managerial oversight' oftewel een 'lage span of control'.

\section{Resultaten}

\section{Gemiddelden en Pearson-correlaties}

Zoals uit Tabel 1a en $1 \mathrm{~b}$ valt af te leiden wordt de zorgvuldigheid van het financieel beheer met gemiddeld 4,60 iets lager beoordeeld door de respondenten dan de zorgvuldigheid van het materieel beheer met gemiddeld 4,88. Het gemiddelde op de gemeten schaal van de frequentie van het aantal onzorgvuldigheden in het beheer ligt bij financieel beheer iets lager dan bij materieel beheer (respectievelijk 2,18 en $2,56)$. Volgens de frequentieverdeling blijkt $56 \%$ van de respondenten aan te geven dat er minstens maandelijks onzorgvuldigheden plaatsvinden. Dit percentage ligt bij materieel beheer iets lager, namelijk op bijna $48 \%$. Het gemiddelde op de gemeten schaal van de besparingsmogelijkheden in het beheer ligt voor materieel beheer met 12,41 hoger dan voor financieel beheer met 7,60. Uit de frequentieverdeling blijkt verder dat $41 \%$ van de respondenten in het financieel beheer en $56 \%$ van de respondenten in het materieel beheer aangeeft dat er meer dan $5 \%$ op de uitgaven bespaard zou kunnen worden.

\section{Tabel 1a Gemiddelden en Pearson-correlaties financieel beheer}

\begin{tabular}{|c|c|c|c|c|c|c|c|c|c|c|c|}
\hline & Variabele & Gem. & S.D. & $\mathbf{N}$ & 1 & 2 & 3 & 4 & 5 & 6 & 7 \\
\hline 1 & Zorgvuldigheid FB & 4,60 & 0,75 & 327 & & & & & & & \\
\hline 2 & Frequentie onzorgvuldigheden FB & 2,18 & 2,36 & 329 & $-0,09$ & & & & & & \\
\hline 3 & Besparingsmogelijkheden FB & 7,60 & 8,83 & 239 & $-0,48^{\star \star}$ & 0,10 & & & & & \\
\hline 4 & Militaire professionele cultuur & 5,21 & 3,38 & 556 & $-0,01$ & $-0,20^{\star \star}$ & 0,03 & & & & \\
\hline 5 & Soft-controls FB & 4,36 & 0,62 & 465 & $0,52^{\star \star}$ & 0,09 & $-0,35^{\star *}$ & $-0,12^{\star}$ & & & \\
\hline 6 & Hard-controls & 3,84 & 1,36 & 553 & $0,35^{* *}$ & $0,31^{* *}$ & $-0,20^{* *}$ & $-0,23^{\star *}$ & $0,42^{\star \star}$ & & \\
\hline 7 & Kostenbewustzijn & 3,83 & 0,97 & 598 & $0,13^{*}$ & 0,10 & $-0,17^{\star *}$ & $-0,07$ & 0,05 & $0,13^{\star \star}$ & \\
\hline
\end{tabular}




\section{Tabel 1b Gemiddelden en Pearson-correlaties materieel beheer}

\begin{tabular}{|c|c|c|c|c|c|c|c|c|c|c|c|}
\hline & Variabele & Gem. & S.D. & N & 1 & 2 & 3 & 4 & 5 & 6 & 7 \\
\hline 1 & Zorgvuldigheid MB & 4,88 & 0,78 & 272 & & & & & & & \\
\hline 2 & Frequentie onzorgvuldigheden MB & 2,56 & 2,55 & 270 & $-0,23^{\star *}$ & & & & & & \\
\hline 3 & Besparingsmogelijkheden MB & 12,41 & 13,61 & 178 & $-0,19^{*}$ & $0,25^{\star \star}$ & & & & & \\
\hline 4 & Militaire professionele cultuur & 5,21 & 3,38 & 556 & 0,08 & 0,10 & $-0,01$ & & & & \\
\hline 5 & Soft-controls MB & 4,36 & 0,62 & 465 & $0,35^{\star \star}$ & $-0,25^{\star \star}$ & $-0,31^{\star *}$ & $-0,11^{*}$ & & & \\
\hline 6 & Hard-controls & 3,84 & 1,36 & 553 & $0,19^{* \star}$ & 0,05 & $-0,09$ & $-0,23^{\star *}$ & $0,41^{\star \star}$ & & \\
\hline 7 & Kostenbewustzijn & 3,83 & 0,97 & 598 & 0,08 & $-0,00$ & $-0,11$ & $-0,07$ & 0,03 & $0,13^{\star \star}$ & \\
\hline
\end{tabular}

De correlaties tussen de drie afhankelijke variabelen per soort beheer zijn niet dermate hoog dat het aanleiding geeft deze drie constructen samen te voegen. De hoogste correlatie $(-0,48)$, te weten tussen zorgvuldigheid en besparingsmogelijkheden in het financieel beheer blijft onder de norm van 0,5 .

\section{Mediatie-effect kostenbewustzijn}

Om na te gaan of kostenbewustzijn een mediatie-effect heeft in de relatie tussen militaire professionele cultuur en financieel en materieel beheer is een regressieanalyse uitgevoerd tussen professionele cultuur en kostenbewustzijn. Er blijkt echter geen significante relatie hiertussen te zijn $(\beta=-0,07 ; p=0,11)$. In het vervolg van de analyses is daarom de relatie tussen militaire cultuur en beheer direct getoetst. Dit geldt ook voor de relatie tussen kostenbewustzijn en beheer.

\section{Hiërarchische meervoudige regressie}

Met behulp van hiërarchische meervoudige regressie zijn vier modellen getest: Model 1 bevat alleen de controlevariabelen; model 2 voegt militaire professionele cultuur daaraan toe; in model 3 zijn hard- en soft-controls toegevoegd; bij model 4 is kostenbewustzijn opgenomen. Dit resulteert in de volgende vier regressievergelijkingen:

Model 1: $Y=\beta_{1} X_{1}+\beta_{2} X_{2}+\beta_{3} X_{3}+\beta_{4} X_{4}+c$

Model 2: $Y=\beta_{1} X_{1}+\beta_{2} X_{2}+\beta_{3} X_{3}+\beta_{4} X_{4}+\beta_{5} X_{5}+c$

Model 3: $Y=\beta_{1} X_{1}+\beta_{2} X_{2}+\beta_{3} X_{3}+\beta_{4} X_{4}+\beta_{5} X_{5}+\beta_{6} X_{6}+c$ Model 4: $Y=\beta_{1} X_{1}+\beta_{2} X_{2}+\beta_{3} X_{3}+\beta_{4} X_{4}+\beta_{5} X_{5}+\beta_{6} X_{6}+$ $\beta_{7} X_{7}+c$

$\mathrm{X}_{1}=$ geslacht, $\mathrm{X}_{2}=$ leeftijd, $\mathrm{X}_{3}=$ opleidingsniveau, $\mathrm{X}_{4}=$ span of control, $X_{5}=$ militaire professionele cultuur, $\mathrm{X}_{6}=$ hard-controls en soft-controls, $\mathrm{X}_{7}=$ kostenbewustzijn, c = constante

Tabel 2 laat zien dat er geen significant verband bestaat tussen militaire cultuur en de mate waarin de respondenten het financieel beheer als zorgvuldig beoordelen. Evenmin is er een significante relatie tussen kostenbewustzijn en financieel beheer. Met betrekking tot hard-controls wordt alleen ondersteuning gevon- den voor de relatie met de frequentie van de onzorgvuldigheden in het financieel beheer. Echter in plaats van negatief is deze relatie positief, hetgeen betekent dat naarmate de hard-controls qua opzet, bestaan en werking als beter worden beoordeeld door de respondenten, er meer onzorgvuldigheden door hen worden geconstateerd. Ten aanzien van de soft-controls is er wat betreft de zorgvuldigheid van het financieel beheer en de besparingsmogelijkheden in het financieel beheer een significant, respectievelijk positief en negatief, verband aanwezig.

Tabel 3 laat zien dat er een significant verband bestaat tussen militaire cultuur en de mate waarin de respondenten het materieel beheer als zorgvuldig beoordelen. Een hoge mate van militair professionele cultuur leidt tot een positieve beoordeling van het materieel beheer. We hadden echter de relatie tussen militaire cultuur en zorgvuldig beheer andersom verondersteld. Er is geen relatie gevonden tussen kostenbewustzijn en materieel beheer. Met betrekking tot hard-controls wordt alleen ondersteuning gevonden voor de relatie met de frequentie van de onzorgvuldigheden in het materieel beheer. Echter in plaats van een negatief te verwachten verband is deze relatie positief, hetgeen betekent dat naarmate de hard-controls qua opzet, bestaan en werking als beter worden beoordeeld door de respondenten, er meer onzorgvuldigheden door hen worden geconstateerd. Ten aanzien van de soft-controls zijn er significante relaties met alle drie de constructen van materieel beheer, te weten de zorgvuldigheid, de frequentie van de onzorgvuldigheden en de besparingsmogelijkheden.

\section{Regressie met interactie-effecten}

Nu blijkt dat hard- en soft-controls invloed hebben op de zorgvuldigheid van het beheer, is het ook interessant na te gaan of hard- en soft-controls een positieve invloed hebben op de relatie tussen militaire professionele cultuur en zorgvuldig beheer. Hiertoe zijn regressieanalyses met interactie-effecten uitgevoerd. ${ }^{5}$

Uit figuur 4a en $4 \mathrm{~b}$ blijkt dat zowel hard- als soft-controls een interactie-effect hebben op de relatie tussen militaire professionele cultuur en financieel beheer. 
Tabel 2 Resultaten regressieanalyse financieel beheer

\begin{tabular}{|c|c|c|c|c|c|c|c|c|c|c|c|c|}
\hline & \multicolumn{4}{|c|}{ Zorgvuldigheid FB } & \multicolumn{4}{|c|}{ Frequentie onzorgvuldigheden FB } & \multicolumn{4}{|c|}{ Besparingsmogelijkheden FB } \\
\hline & Model 1 & Model 2 & Model 3 & Model 4 & Model 1 & Model 2 & Model 3 & Model 4 & Model 1 & Model 2 & Model 3 & Model 4 \\
\hline Constant & $3,57^{\star \star \star}$ & $3,71^{\star \star \star}$ & $1,22^{\star \star}$ & $1,23^{\star \star}$ & 0,79 & 1,51 & 1,58 & 1,34 & $23,39 * \star \star$ & $20,87^{\star \star \star}$ & $39,97^{\star \star \star}$ & $44,34^{\star \star \star}$ \\
\hline Geslacht & 0,07 & 0,09 & 0,08 & 0,08 & $-0,10$ & $-0,06$ & $-0,06$ & $-0,07$ & $-0,17^{*}$ & $-0,19 *$ & $-0,17^{\star}$ & $-0,15$ \\
\hline Leeftijd & 0,12 & 0,09 & 0,02 & 0,02 & 0,13 & 0,07 & 0,04 & 0,04 & $-0,03$ & 0,01 & 0,02 & 0,01 \\
\hline Opleidingsniveau & 0,11 & 0,09 & 0,02 & 0,02 & $0,18^{*}$ & $0,16^{*}$ & 0,13 & 0,12 & $-0,23^{\star \star}$ & $-0,22^{*}$ & $-0,17^{\star}$ & $-0,14$ \\
\hline Span of control & 0,08 & 0,10 & 0,09 & 0,09 & $-0,21^{\star \star}$ & $-0,17^{\star}$ & $-0,19^{\star}$ & $-0,19^{\star}$ & 0,02 & $-0,00$ & $-0,03$ & $-0,03$ \\
\hline MPC & & $-0,08$ & 0,04 & 0,04 & & $-0,16^{*}$ & $-0,09$ & $-0,09$ & & 0,11 & 0,08 & 0,07 \\
\hline Hard controls & & & 0,08 & 0,08 & & & $0,24^{\star *}$ & $0,24^{\star \star}$ & & & 0,11 & 0,10 \\
\hline Soft controls FB & & & $0,48^{\star \star *}$ & $0,48^{\star \star *}$ & & & $-0,08$ & $-0,07$ & & & $-0,35^{\star \star \star}$ & $-0,37^{\star \star \star}$ \\
\hline Kostenbewustzijn & & & & $-0,00$ & & & & 0,03 & & & & $-0,11$ \\
\hline $\mathrm{R}^{2}$ & 0,04 & 0,05 & 0,30 & 0,30 & 0,06 & 0,08 & 0,12 & 0,12 & 0,08 & 0,09 & 0,18 & 0,19 \\
\hline Adjusted R² & 0,03 & 0,03 & 0,27 & 0,27 & 0,05 & 0,06 & 0,09 & 0,09 & 0,06 & 0,06 & 0,14 & 0,14 \\
\hline F-waarde & 2,40 & 2,16 & $12,70^{\star \star \star}$ & $11,06^{\star \star \star}$ & $3,71^{\star \star}$ & $3,92^{\star \star}$ & $4,23^{\star \star \star}$ & $3,72^{\star \star \star}$ & $3,24^{*}$ & $2,90^{*}$ & $4,51^{\star \star \star}$ & $4,18^{\star \star \star}$ \\
\hline N & 220 & 220 & 220 & 220 & 221 & 221 & 221 & 221 & 153 & 153 & 153 & 153 \\
\hline
\end{tabular}

Tabel 3 Resultaten regressieanalyse materieel beheer

\begin{tabular}{|c|c|c|c|c|c|c|c|c|c|c|c|c|}
\hline & \multicolumn{4}{|c|}{ Zorgvuldigheid MB } & \multicolumn{4}{|c|}{ Frequentie onzorgvuldigheden MB } & \multicolumn{4}{|c|}{ Besparingsmogelfjkheden MB } \\
\hline & Model 1 & Model 2 & Model 3 & Model 4 & Model 1 & Model 2 & Model 3 & Model 4 & Model 1 & Model 2 & Model 3 & Model 4 \\
\hline Constant & $4,63^{\star \star \star}$ & $4,37^{\star \star \star}$ & $2,57^{\star \star \star}$ & $2,44^{\star \star \star}$ & 2,78 & 2,26 & $7,00^{\star \star \star}$ & $6,13^{\star \star}$ & 18,73 & 19,80 & $53,42^{\star \star \star}$ & $56,41^{* *}$ \\
\hline Geslacht & 0,01 & $-0,02$ & 0,01 & 0,01 & 0,02 & 0,01 & $-0,01$ & $-0,00$ & 0,09 & 0,10 & 0,07 & 0,06 \\
\hline Leeftijd & 0,04 & 0,10 & 0,06 & 0,06 & $-0,01$ & 0,02 & 0,01 & 0,01 & $-0,01$ & $-0,02$ & $-0,07$ & $-0,07$ \\
\hline Opleidingsniveau & 0,01 & 0,02 & $-0,05$ & $-0,06$ & $-0,16$ & $-0,15$ & $-0,12$ & $-0,13$ & $-0,22$ & $-0,22$ & $-0,21$ & $-0,20$ \\
\hline Span of control & 0,04 & 0,01 & 0,00 & 0,01 & 0,08 & 0,07 & 0,06 & 0,06 & $-0,07$ & $-0,06$ & $-0,05$ & $-0,05$ \\
\hline MPC & & $0,16^{*}$ & $0,19^{*}$ & $0,19 *$ & & 0,08 & 0,09 & 0,09 & & $-0,03$ & $-0,05$ & $-0,05$ \\
\hline Hard controls & & & 0,14 & 0,14 & & & $0,16^{*}$ & $0,16^{*}$ & & & 0,11 & 0,11 \\
\hline Soft controls MB & & & $0,31^{\star \star *}$ & $0,31^{\star \star *}$ & & & $-0,34^{\star \star \star}$ & $-0,33^{\star \star \star}$ & & & $-0,35^{\star \star \star}$ & $-0,36^{\star \star \star *}$ \\
\hline Kostenbewustzijn & & & & 0,03 & & & & 0,07 & & & & $-0,04$ \\
\hline $\mathrm{R}^{2}$ & 0,00 & 0,03 & 0,15 & 0,15 & 0,02 & 0,03 & 0,13 & 0,14 & 0,08 & 0,08 & 0,19 & 0,19 \\
\hline Adjusted $\mathrm{R}^{2}$ & $-0,02$ & $-0,00$ & 0,12 & 0,11 & $-0,00$ & $-0,00$ & 0,10 & 0,10 & 0,05 & 0,04 & 0,13 & 0,13 \\
\hline F-waarde & 0,13 & 0,88 & $4,42^{\star \star \star}$ & $3,87^{\star \star \star}$ & 0,98 & 0,96 & $3,70^{\star \star}$ & $3,35^{\star \star}$ & 2,25 & 1,80 & $3,35^{\star \star}$ & $2,93^{\star \star}$ \\
\hline $\mathrm{N}$ & 179 & 179 & 179 & 179 & 175 & 175 & 175 & 175 & 107 & 107 & 107 & 107 \\
\hline
\end{tabular}

Naarmate er meer gebruik wordt gemaakt van harden soft-controls geeft men aan minder op de uitgaven te kunnen besparen. Bij de hard-controls treedt dit effect zowel op bij mensen waarbij sprake is van een lage mate van militaire professionele cultuur als bij mensen waarbij sprake is van een hoge mate van militaire professionele cultuur. Het effect is echter bij deze laatste groep iets geringer. De hard-controls hebben dus iets meer effect op de burgermedewerkers en de militairen in de ondersteunende functies dan op de mili- tairen in gevechtsfuncties. Bij soft-controls is het verschil van dit effect veel groter. Soft-controls hebben dus veel meer effect op de burgermedewerkers en de militairen in de ondersteunende functies dan op de militairen in gevechtsfuncties.

Uit figuur 4c blijkt dat alleen de mate van beheersing door soft-controls invloed heeft op de relatie tussen militaire professionele cultuur en de beoordeling die men geeft van het materieel beheer. 
Figuur 4a en 4b Interactie-effect hard-controls (figuur 4a) en soft-controls (figuur 4b) op besparingsmogelijkheden financieel beheer

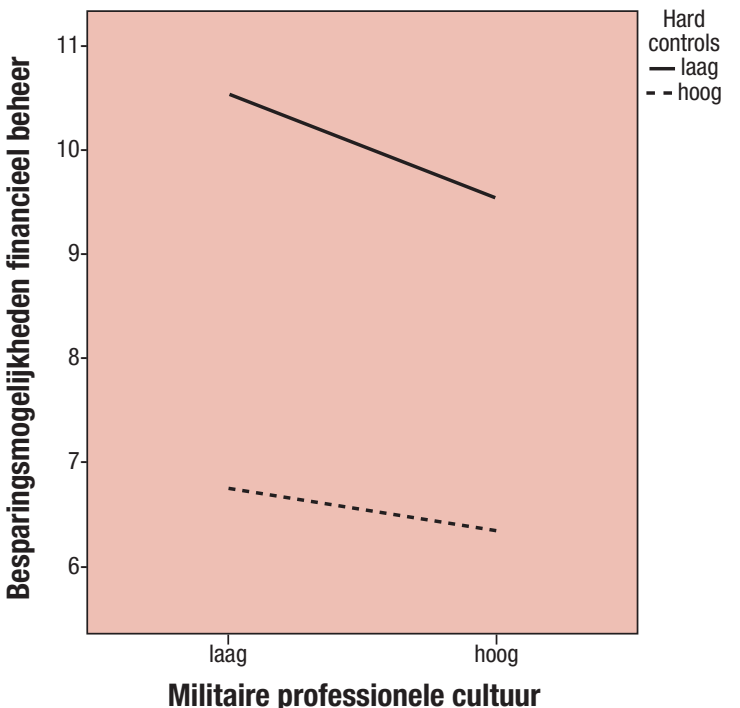

Figuur 4c Interactie-effect soft-controls op beoordeling materieel beheer

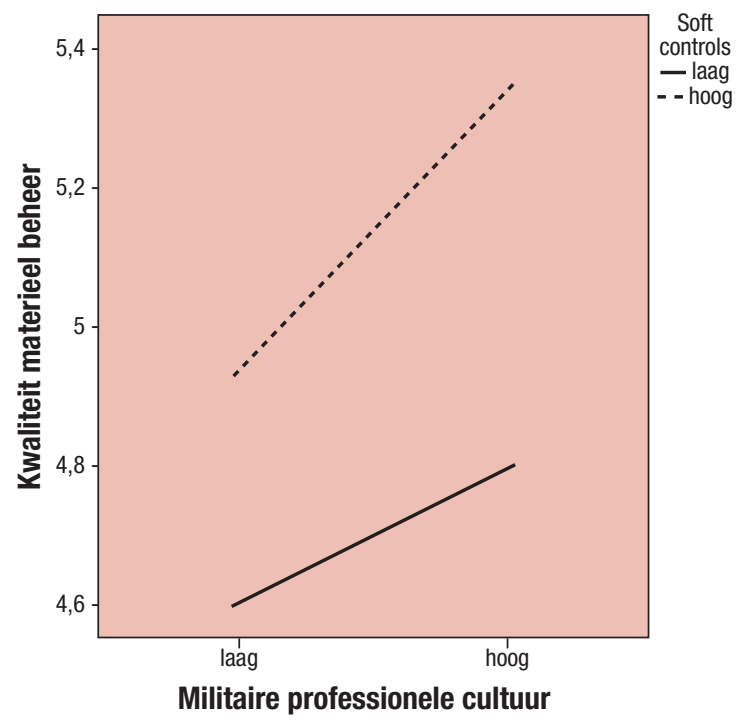

Naarmate er meer gebruik wordt gemaakt van softcontrols geeft men een positievere beoordeling van het materieel beheer. Dit effect is groter bij mensen waarbij sprake is van een hoge mate van militaire professionele cultuur en minder bij mensen waarbij sprake is van een lage mate van militaire professionele cultuur. De soft-controls hebben dus meer effect op de militairen in gevechtsfuncties dan op de burgermedewerkers en de militairen in de ondersteunende functies. Dit is te verklaren uit het feit dat met name militairen in gevechtsfuncties heel nauw betrokken zijn bij hun materieel.

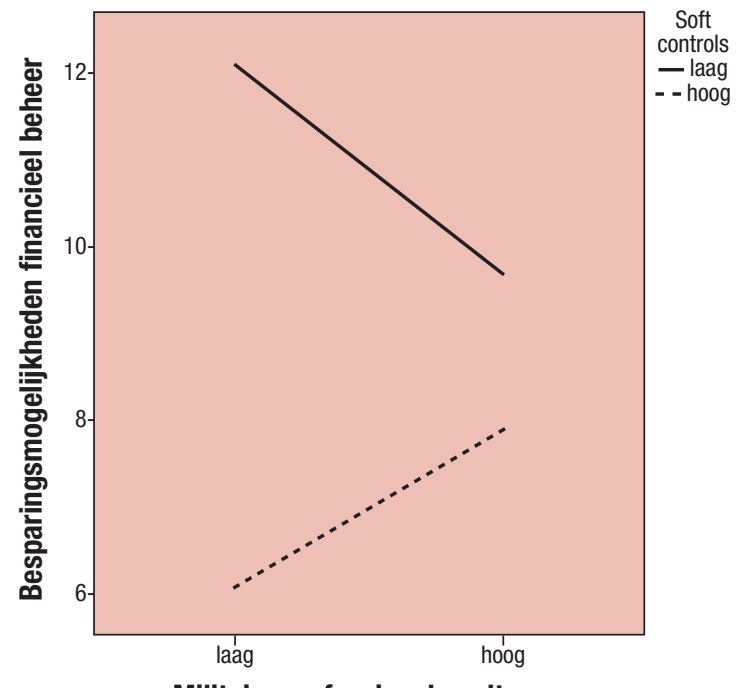

Militaire professionele cultuur

\section{Conclusies en implicaties}

Het doel van dit onderzoek was om na te gaan welke invloed harde en zachte beheersingsmaatregelen hebben op de zorgvuldigheid van het financieel en materieel beheer bij Defensie.

Het is opvallend dat de hard-controls, vaak geen, en wat betreft de frequentie van het aantal onzorgvuldigheden zelfs een negatieve, invloed hebben op het financieel en materieel beheer. De gevonden negatieve relatie betekent dus dat hoe meer er volgens de respondenten gebruik wordt gemaakt van hard-controls, hoe vaker men zegt onzorgvuldigheden in het beheer aan te treffen. Daarmee wordt hypothese 1 niet ondersteund. Dit onverwachte omgekeerde effect laat zich in navolging van Soeters (1983) verklaren door het probleem van de tijdvolgorde. In onze veronderstelling omtrent het effect van deze variabele gaan hard-controls in tijd vooraf aan vermindering van het aantal geconstateerde onzorgvuldigheden. $\mathrm{Nu}$ is het waarschijnlijk dat organisaties pas hard-controls gaan inzetten op het moment dat men het aantal geconstateerde onzorgvuldigheden als problematisch gaat ervaren. Een mogelijke andere verklaring hiervoor is dat een hard-control als een goed werkend interne controlemechanisme er juist voor zorgt dat onzorgvuldigheden zichtbaar worden. Er kan een cyclisch proces ontstaan: waar meer onzorgvuldigheden aan het licht komen, worden ook meer hard-controls ingezet, waardoor weer meer onzorgvuldigheden aan het licht komen. Het lijkt erop dat de hard-controls daarmee vooral een detectiefunctie vervullen. Overigens blijkt de verklarende waarde van het model laag met een $R^{2}$ van $12 \%$ bij financieel beheer en een $R^{2}$ van $13 \%$ bij materieel beheer. 
De soft-controls voldoen wel geheel aan de verwachting zoals geformuleerd in hypothese 2 met een positieve invloed op nagenoeg alle afhankelijke variabelen van zowel het financieel als het materieel beheer. Naarmate de respondenten vinden dat binnen hun organisatie-eenheid soft-controls meer zijn ingebed, geven ze een positievere beoordeling van het financieel en materieel beheer en geven ze ook aan dat er niet zoveel op de uitgaven kan worden bespaard.

Voor het eerste deel van hypothese 3, de vermeende relatie tussen militaire professionele cultuur en kostenbewustzijn, is geen ondersteuning gevonden. Er is ook geen ondersteuning gevonden voor het tweede deel van hypothese 3, namelijk de relatie tussen kostenbewustzijn en zorgvuldig beheer. Kostenbewustzijn blijkt ook geen mediatie-effect te hebben tussen militaire cultuur en zorgvuldig beheer. Dit kan mogelijk worden verklaard doordat kostenbewustzijn op het niveau van de respondenten die in dit onderzoek zijn bevraagd niet zo relevant is. Budgetten en financiële gevolgen zijn nu eenmaal hoger in de organisatie belegd, waardoor er op het niveau van de respondenten geen kosteninzicht is, laat staan kostenbewustzijn. Er is wel een rechtstreekse relatie gevonden tussen militaire professionele cultuur en zorgvuldig materieel beheer. Een hoge mate van militair professionele cultuur bij de respondenten leidt tot een positievere beoordeling van het materieel beheer. We hadden deze relatie echter negatief verondersteld. Een mogelijke verklaring is dat met name militairen in gevechtsfuncties heel nauw zijn betrokken bij hun materieel. Immers zonder wapen, zonder munitie en zonder kogelwerend vest is er geen effectieve en veilige operatie.

De hard-controls hebben alleen in het financieel beheer een interactie-effect. Ze blijken iets meer effect op de burgermedewerkers en de militairen in de ondersteunende functies dan op de militairen in gevechtsfuncties te hebben. Hiermee wordt dus een omgekeerd effect waargenomen dan we in hypothese 4 hadden verondersteld. Soft-controls hebben een interactie-effect op beide soorten van beheer. Maar zij hebben daarbij juist meer effect op de militairen in gevechtsfuncties dan op de burgermedewerkers en de militairen in de ondersteunende functies. Hypothese 5 wordt daarmee volledig ondersteund.

Dit onderzoek wijst uit dat beide soorten beheersingsmaatregelen een rol spelen bij de oplossing voor de problemen in het financieel en materieel beheer bij Defensie. Aangezien soft-controls een positieve invloed blijken te hebben op vijf van de zes afhankelijke variabelen, zou vooral daarin de oplossing van de beheersingsproblematiek bij Defensie moeten worden gezocht. Het is daarom wenselijk dat controllers en auditors van Defensie de aanwezigheid van soft-controls betrekken bij de inrichting en beoordeling van het totale complex aan beheersingsmaatregelen. Aan- gezien dit nieuw is voor Defensie lijkt ons scholing en educatie op dit gebied noodzakelijk. Alle leidinggevenden bij Defensie willen we oproepen deze beoordeling van controllers en auditors nauwgezet te volgen. Maar nog meer zouden we hen adviseren zelf een proactieve houding aan te nemen. Vooral commandanten zijn immers degenen die het goede voorbeeld kunnen geven, bespreekbaarheid binnen een eenheid kunnen creëren en negatief gedrag kunnen sanctioneren dan wel positief gedrag belonen.

Om aan het bezwaar van cross-sectioneel onderzoek tegemoet te komen, is het aan te bevelen de meting op een later moment te herhalen en het onderzoek daarmee een longitudinaal karakter te geven. Gezien de vele interne wisselingen van met name het militaire personeel, zal een zuivere herhaling echter niet mogelijk zijn. Toch denken we dat een herhaling van de meting bij Defensie waardevol inzicht geeft in de ontwikkeling van de beheersingsmaatregelen en de zorgvuldigheid van het beheer bij de onderzochte eenheden.

Een andere manier om opvolging te geven aan dit onderzoek is door herhaling in andere organisaties. Het is de verwachting dat in het bedrijfsleven kostenbewustzijn wel van invloed is op zorgvuldigheid van het middelenbeheer. Als een bedrijf voor haar voortbestaan afhankelijk is van winst, kan dat alleen als er voldoende omzet staat tegenover de daarmee samenhangende kosten. In markten waarin een bedrijf zelf geen of weinig invloed heeft op de prijs van diens producten of diensten, is het beheersen van de kosten van 'levensbelang'. Daarnaast is het de verwachting dat bij andere publieke en door een professionele cultuur gedomineerde organisaties, zoals de brandweer en de politie, vergelijkbare verbanden tussen cultuur, soorten beheersingsmaatregelen en zorgvuldigheid van beheer zijn te vinden als bij Defensie. Dit zou dan verder bewijs geven voor de harde noodzaak van soft-controls.

\section{BIJLAGE 1 ITEMS PER VARIABELE}

\section{Afhankelijke variabelen financieel beheer}

\section{Frequentie onzorgvuldigheden financieel beheer}

( van $1=$ nooit tot $6=$ dagelijks)

1. Hoe vaak wordt u bij uw eenheid geconfronteerd met onzorgvuldigheden in het financieel beheer?

\section{Zorgvuldigheid financieel beheer}

(van 1 = zeer onzorgvuldig tot $6=$ zeer zorgvuldig)

1. Ik vind bij mijn eenheid het beheer van uitgaven

2. Ik vind bij mijn eenheid het beheer van verplichtingen

3. Ik vind bij mijn eenheid het beheer van vorderingen en ontvangsten

4. Ik vind bij mijn eenheid het beheer van voorschotten 
5. Ik vind bij mijn eenheid het beheer van rekeningen buiten begrotingsverband

6. Ik vind bij mijn eenheid het beheer van liquide middelen

Besparingsmogelijkheden financieel beheer (van 0 tot $100 \%$ )

1. Hoeveel procent zou uw eenheid op de uitgaven kunnen besparen als er sprake is van zorgvuldig financieel beheer?

\section{Afhankelijke variabelen materieel beheer}

Frequentie onzorgvuldigheden materieel beheer ( van $1=$ nooit tot $6=$ dagelijks)

1. Hoe vaak wordt u bij uw eenheid geconfronteerd met onzorgvuldigheden in het materieel beheer?

Zorgvuldigheid materieel beheer

(van 1 = zeer onzorgvuldig tot 6 = zeer zorgvuldig)

1. Ik vind bij mijn eenheid het munitiebeheer

2. Ik vind bij mijn eenheid het wapenbeheer

3. Ik vind bij mijn eenheid het cryptobeheer

4. Ik vind bij mijn eenheid het materieel beheer algemeen (het materieel beheer m.u.v. munitie-, wapenen cryptobeheer)

\section{Besparingsmogelijkheden materieel beheer} (van 0 tot $100 \%$ )

1. Hoeveel procent zou uw eenheid op de uitgaven kunnen besparen als er sprake is van zorgvuldig materieel beheer?

\section{Onafhankelijke variabele, hard controls}

(van $0=i k$ weet het niet, $1=$ volledig mee oneens tot $6=$ vol ledig mee eens)

\section{Controletechnische functiescheiding. Binnen mijn eenheid:}

a. is het voldoende helder wat wordt verstaan onder controletechnische functiescheiding in het finan$\mathrm{cieel} /$ materieel beheer.

b. is de controletechnische functiescheiding in het financieel/materieel beheer geregeld met behulp van een bevoegdhedenmatrix.

c. wordt controletechnische functiescheiding in het financieel/materieel beheer toegepast.

d. draagt de controletechnische functiescheiding bij aan zorgvuldig financieel/materieel beheer.

2. Interne controle. Binnen mijn eenheid:

a. is het voldoende helder wat wordt verstaan onder interne controle op het financieel/materieel beheer.

b. zijn de activiteiten van de interne controle organen vastgelegd in een plan.

c. vindt interne controle plaats op het financieel/ materieel beheer door OIB en/of ADD.

d. draagt de interne controle bij aan zorgvuldig financieel/materieel beheer.

\section{Procedurebeschrijvingen / richtlijnen / regelgeving. Binnen mijn eenheid:}

a. zijn de procedurebeschrijvingen / richtlijnen / regelgevingen voor het financieel/materieel beheer voldoende helder.

b. bestaan verschillende procedurebeschrijvingen / richtlijnen / regelgevingen voor het financieel/ materieel beheer.

c. passen we de procedurebeschrijvingen / richtlijnen / regelgevingen toe op het financieel/materieel beheer.

d. dragen de procedurebeschrijvingen / richtlijnen / regelgevingen bij aan zorgvuldig financieel/materieel beheer.

4. Registratie. Binnen mijn eenheid:

a. is het voldoende helder wat wordt verstaan onder registratie in een geautomatiseerd systeem.

b. hebben we de beschikking over een geautomatiseerd systeem om te registreren.

c. vindt registratie plaats in een geautomatiseerd systeem.

d. draagt de registratie bij aan zorgvuldig financieel/materieel beheer.

5. Risico-analyse. Binnen mijn eenheid:

a. is het voldoende helder wat wordt verstaan onder een risico-analyse om de knelpunten in het financieel/materieel beheer te bepalen.

b. voeren we ieder jaar een risico-analyse uit om de knelpunten in het financieel/materieel beheer te bepalen.

c. krijgen door het uitvoeren van een risico-analyse de knelpunten in het financieel/materieel beheer specifieke aandacht.

d. draagt het uitvoeren van een risico-analyse om de knelpunten in het financieel/materieel beheer te bepalen, bij aan zorgvuldig financieel/materieel beheer.

\section{Onafhankelijke variabele, soft controls}

(van $1=$ volledig mee oneens tot $6=$ volledig mee eens)

\section{Helderbeid financieel beheer}

1. Het is mij voldoende helder wat wordt verstaan onder zorgvuldig beheer van uitgaven.

2. Het is mij voldoende helder wat wordt verstaan onder zorgvuldig beheer van verplichtingen

3 . Het is mij voldoende helder wat wordt verstaan onder zorgvuldig beheer van vorderingen en ontvangsten.

4. Het is mij voldoende helder wat wordt verstaan onder zorgvuldig beheer van voorschotten.

5 . Het is mij voldoende helder wat wordt verstaan on- 
der zorgvuldig beheer van rekeningen buiten begrotingsverband.

6 . Het is mij voldoende helder wat wordt verstaan onder zorgvuldig beheer van liquide middelen.

\section{Helderheid materieel beheer}

1 . Het is mij voldoende helder wat wordt verstaan onder zorgvuldig munitiebeheer.

2. Het is mij voldoende helder wat wordt verstaan onder zorgvuldig wapenbeheer.

3 . Het is mij voldoende helder wat wordt verstaan onder zorgvuldig cryptobeheer.

4. Het is mij voldoende helder wat wordt verstaan onder zorgvuldig materieel beheer algemeen.

\section{Voorbeeldgedrag}

1. Mijn direct leidinggevende geeft het goede voorbeeld m.b.t. het financieel/materieel beheer.

2. Mijn direct leidinggevende benadrukt het belang van financieel / materieel beheer op overtuigende wijze.

3. Mijn direct leidinggevende zou nooit onzorgvuldig financieel/materieel beheer accepteren om zo de organisatiedoelstellingen te halen.

4. Mijn direct leidinggevende komt zijn verantwoordelijkheden in het financieel/materieel beheer na.

5. Het managementteam van mijn eenheid geeft het goede voorbeeld m.b.t. het financieel/materieel beheer.

6. Het managementteam van mijn eenheid benadrukt het belang van financieel/materieel beheer op overtuigende wijze.

\section{Uitvoerbaarheid}

1. Ik ben voldoende opgeleid om mijn rol in het finan$\mathrm{cieel} /$ materieel beheer naar behoren uit te voeren.

2. Ik heb voldoende werkervaring om mijn rol in het financieel/materieel beheer naar behoren uit te voeren.

3. Ik heb voldoende tijd ter beschikking om mijn rol in het financieel/materieel beheer naar behoren uit te voeren.

4. De ICT-middelen die mij ter beschikking staan ondersteunen mij om mijn rol in het financieel/materieel beheer naar behoren uit te voeren.

\section{Betrokkenbeid}

1. Binnen mijn eenheid is men zeer gecommitteerd aan de bestaande regels en richtlijnen van financieel/materieel beheer.

2. Ik vind zelf zorgvuldig financieel/materieel beheer belangrijk.

3. Binnen mijn eenheid bestaat wederzijds vertrouwen tussen leidinggevenden en medewerkers.

4. Binnen mijn eenheid neemt men de bestaande regels en richtlijnen van financieel/materieel beheer heel serieus.

\section{Transparantie}

1. Als iemand binnen mijn eenheid zich schuldig maakt aan onzorgvuldig financieel/materieel beheer, komt mijn leidinggevende dit te weten.
2. Als iemand binnen mijn eenheid zich schuldig maakt aan onzorgvuldig financieel/materieel beheer, kom ik of een andere collega dit te weten.

3. Als mijn leidinggevende zich schuldig maakt aan onzorgvuldig financieel/materieel beheer, komt iemand in de organisatie dit te weten.

4. Binnen mijn eenheid is men zich voldoende bewust van de risicogebieden in het financieel/materieel beheer.

5. Binnen mijn eenheid vinden adequate controles plaats om onzorgvuldig financieel/materieel beheer te signaleren.

\section{Bespreekbaarheid}

1. Binnen mijn eenheid heb ik de mogelijkheid mijn mening te uiten over zorgvuldig financieel/materieel beheer.

2. Binnen mijn eenheid staat men open voor discussie over dilemma's in het financieel/materieel beheer.

3. Binnen mijn eenheid is voldoende gelegenheid om dilemma's in het financieel/materieel beheer te bespreken.

4. Als er sprake is van onzorgvuldig financieel/materieel beheer, wordt diegene daar op aan gesproken.

5. Als er binnen mijn eenheid niet adequaat wordt gereageerd op gerapporteerd onzorgvuldig financieel/materieel beheer, dan is er voldoende mogelijkheid de zaak ergens anders in de organisatie aan de orde te stellen.

\section{Handhaving}

1. Binnen mijn eenheid worden mensen verantwoordelijk gehouden voor hun acties.

2. Als mijn direct leidinggevende zich schuldig maakt aan onzorgvuldig financieel/materieel beheer, wordt hij/zij gestraft.

3. Succesvolle mensen binnen mijn eenheid houden zich aan de regels van zorgvuldig financieel/materieel beheer.

4. Binnen mijn eenheid wordt zorgvuldig financieel/ materieel beheer beloond.

5. Binnen mijn eenheid worden medewerkers die zich schuldig maken aan onzorgvuldig financieel/materieel beheer, bestraft.

\section{Onafhankelijke variabele, militair professionele cultuur}

1. Bent u militair of burgermedewerker? $(1$ = burger, 2 = militair $)$

2. Hoe vaak bent $\mathrm{u}$ uitgezonden geweest? $(1=$ n.v.t. $/$ nooit, $2=1-3$ keer, $3=>4$ keer

3. Van welk wapen of dienstvak bent $\mathrm{u}$ ? ( $1=$ MA $/ B E Z / M E T E O / A / L O-S / M P S D, 2=E O D D /$ Genie/TD/VBDD/BeT/GNK/LVB/LOG/KMar, 3 = INF/CAV/ART/ZEED/VLO/GRO, 4 = MARNS/KCT/ $L U M B L)$ 
Onafhankelijke variabele, kostenbewustzijn

(van 1 = volledig mee oneens tot 6 = volledig mee eens)

1. Er ligt momenteel te veel nadruk op de kosten binnen mijn eenheid.

2. Binnen mijn eenheid maakt men zich te veel zorgen over de kosten.

3. De leidinggevenden binnen mijn eenheid maken zich te veel zorgen over de kosten.

4. Het is onredelijk om te vragen van defensiemedewerkers om kostenbewust te zijn en tegelijkertijd het beschermen van mensenlevens op de eerste plaats te zetten.

\section{Controlevariabelen}

\section{Geslacht}

Wat is uw geslacht?

$(1=$ man, $2=$ vrouw $)$

\section{Leeftijd}

In welke leeftijdscategorie valt $\mathrm{u}$ ?

$(1=\langle 21,2=21-30,3=31-40,4=41-50,5=51-60,6=\rangle$

61)

\section{Opleidingsniveau}

Wat is het niveau van uw hoogst genoten opleiding?
$(1=L B O / V M B O, 2=M B O / K M S, 3=H B O, 4=K I M /$

$K M A, 5=W O)$

\section{Span of control}

Aan hoeveel mensen geeft u leiding, indien van toepassing?

( $1=$ n.v.t., $2=1-10,3=11-20,4=21-30,5=31-40,6=41$ -

$50,7=>51)$

Drs. J.J.D. Heeren-Bogers is universitair docent Econo-

mie, in het bijzonder op het gebied van management ac-

counting en control, op de Faculteit Militaire Wetenschap-

pen van de Nederlandse Defensie Academie.

Prof. dr. M. Kaptein is hoogleraar Bedriffskunde, in het

bijzonder op het gebied van Bedrijfsethiek en Integriteit-

management, aan de Rotterdam School of Management

van de Erasmus Universiteit. Hij is daarnaast als organisa-

tieadviseur en auditor op het gebied van hard- en soft-

controls werkzaam bij KPMG Forensic \& Integrity.

Prof. dr. J.M.M.L. Soeters is hoogleraar Management \&

Organisatie op de Faculteit Militaire Wetenschappen van

de Nederlandse Defensie Academie. Hij is daarnaast als

hoogleraar verbonden aan de Tilburg School of Social and

Behavioral Studies bij de afdeling Organisation Studies.

\section{Noten}

Bij een bezwaaronderzoek gaat de ARK na wat de oorzaak is van de problemen en of deze structureel van aard zijn. Op grond van de resultaten van dit onderzoek neemt de Algemene Rekenkamer een besluit over het al dan niet maken van bezwaar (ARK, 2013).

2. Bij hypothese 4 en 5 wordt het eventuele mediatie-effect van kostenbewustzijn in de relatie tussen militaire professionele cultuur en zorgvuldig beheer buiten beschouwing gelaten. Er wordt bij hypothese 4 en 5 dus getoetst of er een interactie-effect is van hard- en/of soft-controls op de directe relatie tussen militaire professionele cultuur en zorguuldig beheer. Om die reden is in figuur 1 het construct van kostenbewustzijn met een stippellijn weergegeven.

3. Om tegemoet te komen aan de bezwaren van 'common source bias', zijn per eenheid verschillende vragenlijsten gestuurd aan verschillende soorten respondenten. Zo is aan de commandanten naast de controlevariabelen, militaire professionele cultuur en kostenbewustzijn, alleen om een beoordeling van de afhankelijke variabelen (zowel financieel als materieel beheer) gevraagd. Aan financieel en logistiek specialisten is naast de controlevariabelen, militaire professionele cultuur, kostenbewustzijn en een beoordeling van respectievelijk het financieel of het materieel beheer, ook om een beoordeling van de hard- controls gevraagd. De mensen met een uitvoerende rol in het financieel en materieel beheer hebben de meest uitgebreide vragenlijst ontvangen. Zij zijn naast de controlevariabelen, militaire professionele cultuur, kostenbewustzijn en een beoordeling van respectievelijk het financieel of het materieel beheer, ook om een beoordeling van de hard-controls en de soft-controls gevraagd. Deze werkwijze veroorzaakt een variatie in de $\mathrm{N}$ bij de statistische analyses.

4 De waarden voor de militaire professionele cultuur zijn: 1 is een burger die nooit is uitgezonden, 2 is een militair in een secundair ondersteunende functie die nooit is uitgezonden, 3 is een militair in een secundair ondersteunende functie die 1-3 keer is uitgezonden, 4 is een militair in een secundair ondersteunende functie die $>4$ keer is uitgezonden, 5 is een militair in een primair ondersteunende functie die nooit is uitgezonden, 6 is een militair in een primair ondersteunende functie die 1-3 keer is uitgezonden, 7 is een militair in een primair ondersteunende functie die $>4$ keer is uitgezonden, 8 is een militair in een gevechtsfunctie die nooit is uitgezonden, 9 is een militair in een gevechtsfunctie die 1-3 keer is uitgezonden, 10 is een militair in een gevechtsfunctie die $>4$ keer is uitgezonden, 11 is een militair van de special forces die nooit is uitgezonden, 12 is een militair van de special forces die 1-3 is uitgezonden en 13 is een militair van de special forces die $>4$ keer is uitgezonden.

5. Voor het uitvoeren van regressieanalyses met interactie-effecten zijn eerst de gemiddeldes bepaald van de verschillende constructen. Daarna zïn gecentreerde variabelen gemaakt door van de scores het gemiddelde af te trekken om multicollineariteit te voorkomen. Daarna zijn de productvariabelen (interactietermen) aangemaakt die vervolgens steeds als laatste groep in de hiërarchische regressie zijn toegevoegd. Om de interactie-effecten grafisch te kunnen weergeven zijn dichotome variabelen van de constructen gemaakt door een groep te maken van de laagste score tot de mediaan (laag) en een groep vanaf de mediaan tot de hoogste score (hoog). 
- Algemene Rekenkamer (ARK). (2011). Rapport bij het Jaarverslag 2010 van het Ministerie van Defensie (32 710 X nr. 2). Geraadpleegd op: http://www.rekenkamer.n//Publicaties/ Onderzoeksrapporten/Introducties/2011/05/ Rechtmatigheidsonderzoek_2010/Rapport_ bij_het_Jaarverslag_2010_van_het_Ministerie_van_Defensie .

- Algemene Rekenkamer (ARK). (2013). Verklarende woordenlijst. Geraadpleegd op: http:// www.rekenkamer.n//Publicaties/Dossiers/V/ Verantwoordingsdag/Verklarende_ woordenlijst/B/Bezwaaronderzoek.

- Anthony, R.N. (1965). Planning and control systems: a framework for analysis. Boston, MA: Harvard University, Graduate School of Business Administration.

- Beu, D.S., Buckley, M.R., \& Harvey, M.G. (2003). Ethical decision-making: A multidimensional construct. Business Ethics: A European Review, 12(1), 88-107.

- Bovier, P.A., Martin, D.P., \& Perneger, T.V. (2005). Cost-consciousness among Swiss doctors: A cross-sectional survey. BMC Health Services Research, 5(1), 1-8.

- Cortina, J.M. (1993). What is coefficient alpha? An examination of theory and applications. Journal of Applied Psychology. 78, 98 104.

- Deshpande, S.P. (1997). Managers' perception of proper ethical conduct: the effect of sex, age, and level of education. Journal of Business Ethics, 16(1), 79-85.

- Detert, J. R., Treviño, L.K., Burris, E.R., \& Andiappan, M. (2007). Managerial modes of influence and counterproductivity in organiza- tions: a longitudinal business-unit-level investigation, Journal of Applied Psychology, 92(1), 993-1005.

- Field, A. (2009). Discovering statistics using SPSS. London: Sage Publications Ltd.

- Heus, R.S. de, \& Stremmelaar, M.T.L. (2000). Auditing soft controls (Serie auditing in de praktijk, nr. 8). Deventer: Kluwer.

- Hofstede, G. (1991). Allemaal andersdenkenden. Omgaan met cultuurverschillen. Amsterdam: Contact.

- Jans, E.O.J. (2007). Grondslagen administratieve organisatie. Deel A: algemene beginselen. Groningen: Wolters-Noordhoff.

- Kaptein, M. (2008). Developing and testing a measure for the ethical culture of organizations: The corporate ethical virtues model. Journal of Organizational Behavior, 29(7), 923-947.

- Kim, Y., \& Choi, Y. (2003). Ethical standards appear to change with age and ideology: A survey of practitioners. Public Relations Review, 29(1), 79-89.

- Lawler, E.E., \& Rhode, J.G. (1976). Information and control in organizations. Pacific Palisades, CA: Goodyear Publishing Company.

- Merchant, K.A. (1982). The control function of management. Sloan Management Review, 23, 43-55.

- Ministerie van Defensie (2009). Rekenkamer positief over verbeteringen bij Defensie. Geraadpleegd op http://www.defensie.n//actueel/nieuws/2009/05/19/46131496/Rekenkamer_positief_over_verbeteringen_bii__Defensie.

- Ministerie van Defensie, Bestuursstaf, Hoofd- directie Financiën en Control (2009), Meerjarig verbeterplan financieel beheer, 17 maart 2009.

- Ministerie van Defensie, Bestuursstaf, DMO/ Beleid (2009), Voorschritt materieelbeheer Defensie, Status definitief, versienummer: 2.0.0, 16 juni 2009.

- Ministerie van Financiën, Directie Accountancy Rijksoverheid (2003). Baseline financieel en materieel beheer. 2e herziene druk.

- Mouthaan, E.H.J. (2007). De balans tussen regels en waarden. Maandblad voor Accountancy en Bedriffseconomie, 81(12), 600-607.

- Roth, J. (1998). Soft, dangerous, essential: An interview with Jim Roth. The internal auditor, 55,31-33.

- Schein, E. H. (1985). Organizational culture and leadership. San Fransisco, CA: Jossey Bass.

- Sims, R., \& Brinkmann, J. (2003). Enron ethics (or: culture matters more than codes). Journal of Business Ethics, 45(3), 243-256.

- Snider, D.M. (1999). The future of American military culture: An uninformed debate on military culture. Orbis, 43, 11-26.

- Soeters, J. (1983). Arbeid, organisatie en arbeidsongeschiktheid. Gezondheid \& Samenleving, 4(1), 13-21.

- Soeters, J.L. (2000). Culture in uniformed organizations. In N. Ashkanay, C. Wilerom en M. Peterson (Eds.). Handbook of organizational culture and climate. Thousand Oaks, CA: Sage.

- Vink, H.J., \& Kaptein, M. (2008). Soft controls bij de rijksoverheid: de oorzaken van rechtmatigheidsfouten onderzocht, Maandblad voor Accountancy en Bedrijfseconomie, 82(6), 256-262. 